\title{
Prenatal Bağlanmayı Destekleyici Bakım Uygulamaları
}

\section{Care Practices Supporting Prenatal Attachment}

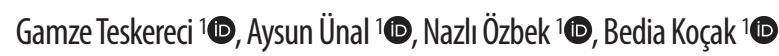

\begin{abstract}
$\ddot{0} z$
Anne-bebek bağlanması, gebelik döneminden başlayıp, doğum ve doğum sonu dönemde devam eden bir süreçtir. Kadın sağlı̆ı alanında çalışan hemşire ve ebelerin prenatal bağlanmanın desteklenmesinde önemli rol ve sorumlulukları bulunmaktadır. Bu derleme ile literatür ışı̆ı̆nda prenatal bağlanmayı değerlendiren ölçüm araçlarııın, etkileyen faktörlerin ve destekleyici kanıta dayalı uygulamaların sunulması amaçlanmıştır. Yapılan literatür incelemesi sonucunda; gebelerde anne-bebek bağlanmasını değerlendiren ve Türkçe geçerlik-güvenirliği yapılmış olan "Maternal-Fetal Bağlanma Ölçeği", "Prenatal Bağlanma Envanteri", "Anne Doğum Öncesi Bağlanma Ölçeği" ve "Prenatal Bağlanma Ölçeği"ne ulaşılmışır. Bu çalışmalarda prenatal bağlanmayı etkileyen pek çok bireysel ve çevresel faktörün olduğu belirlenmiştir. Ulaşılabilen deneysel çalışmalarda prenatal bağlanmayı; fetal hareket sayımı, leopold manevrası uygulaması, gebe eğitimi ve danışmanlık, baba eğitimi, doğuma hazıllık eğitimi, gevşeme egzersizi ve rehberli imgeleme, bilişsel davranış̧ terapiler, yoga ve meditasyon uygulamalarının desteklediği, müzik dinletmenin ise etkilemediği gösterilmiştir. Hemşirelerin düşü̈k prenatal bağlanma riski olan gebelere ucuz ve non-invaziv olan bu uygulamalar hakkında eğitim ve danışmanlık vermesi, gebenin kendisi için seçeceği en uygun yöntemi kullanması için desteklemesi önerilmektedir. Ayrıca ülkemizde prenatal bağlanmada kanıta dayalı uygulamaların etkinliğini test eden çalışmaların sınırlı olduğu, daha fazla randomize kontrollü çalışmalara gereksinim olduğu saptanmıştır.
\end{abstract}

Anahtar sözcükler: Gebelik, hemşire, ebe, maternal-fetal bağlanma, prenatal bağlanma, prenatal bakım

\section{Abstract}

Mother-baby attachment is a process that starts from the pregnancy period and continues in the birth and postpartum period. Nurses working in the field of women's health and midwives have important roles and responsibilities in supporting prenatal attachment. In this review, it is aimed to present the measurement tools, influencing factors and supporting evidence-based applications that evaluate prenatal attachment in the light of literature. As a result of the literature review; "Maternal-Fetal Attachment Scale", "Prenatal Attachment Inventory", "Maternal Prenatal Attachment Scale" and "Prenatal Attachment Scale", which evaluated mother-infant attachment in pregnant women and whose validity and reliability were made in Turkish, were reached. In these studies, it was revealed that many individual and environmental factors of the pregnant woman affected prenatal attachment. In experimental studies available, it was shown that fetal movement count, leopold maneuver practice, pregnancy training and counseling, father training, birth preparation training, relaxation exercise and guided imagery, cognitive behavioral therapies, yoga and meditation practices support prenatal attachment, while listening to music does not affect it. Nurses are recommended to provide training and counseling to pregnant women with low prenatal attachment risk on these cheap and non-invasive practices, and to support the pregnant woman to use the most appropriate method for her. In addition, it was found that studies testing the effectiveness of evidence-based practices in prenatal attachment are limited in our country and more randomized controlled studies are needed.

Keywords: Pregnancy, nurse, midwives, maternal-fetal attachment, prenatal attachment, prenatal care

${ }^{1}$ Akdeniz Üniversitesi, Antalya, Türkiye

$凶$ Gamze Teskereci, Akdeniz Üniversitesi Kumluca Sağlık Bilimleri Fakültesi, Doğum ve Kadın Hastalıkları Hemşireliği Anabilim Dalı, Antalya, Türkiye

gteskereci@akdeniz.edu.tr|0000-0003-0298-9716

Geliş tarihi/Received: 19.02.2021 | Kabul tarihi/Accepted: 05.05.2021 | Çevrimiçi yayın/Published online: 24.06 .2021 
PRENATAL bağlanma, gebe ile fetüs arasında kurulan ilişkiyi tanımlamak için kullanılan bir kavramdır. 1960-1970'li yillarda doğum sırasında bebek ölümleri nedeniyle yas tutan kadınların gözlemlenmesi sonucunda prenatal bağlanma üzerine çeşitli araştırmalar yürütülmeye başlanmıştır. Peppers ve Knapp (1980) tarafından bebeğini kaybeden 65 kadın ile yapilan bir çalı̧̧mada, anne-bebek bağlanmasının neonatal dönemden önce prenatal dönemde başlamış olduğunu kanıtlamıştır. Peppers ve Knapp (1980), prenatal bağlanmayı etkileyebilecek dokuz davranıştan söz etmiştir. Bunlar; gebeliğin planlanması, istenen bir gebelik olması, gebeliğin kabul edilmesi, fetal hareketlerin hissedilmesi, fetüsün ayrı bir birey olarak kabul edilmesi, doğumun gerçekleşmesi, bebeğin görülmesi, bebeğe dokunulması ve bebeğe bakım verilmesidir.

Prenatal bağlanmanın teorik yapısının kurucusu olan Rubin (1975), kadınların prenatal dönemde dört özel görevinin olduğunu vurgulamıştır. Bunlar; (a) Gebelik süresince kendisi ve bebeği için güvenli bir geçiş arayışı, (b) Bebeğin diğerleri tarafindan kabul edilmesinin sağlanması (c) Fetüs ile içsel bağ kurulması (d) Kendini bebeğe adamasıdır. Rubin'den sonra Muller, Cranley ve Condon gibi araştırmacilarda bu alanda çalışmışlardır (Cranley 1981, Condon 1993, Muller 1993). Cranley (1981), Maternal-Fetal Bağlanma (MFB) kavramını gebelik döneminde kadının bebeğine davranışları yoluyla bağlanarak yakın bir ilişki kurması ve etkileşime girmesi olarak tanımlamıştır. Cranley (1981)'e göre MFB, annenin fetüsü kendinden ve bedeninden farklı olarak algılaması, onunla iletişime girmesi, fetüsün özelliklerini yorumlaması, kendini adaması, annelik rolünü benimsemesi gibi farklı durumları kapsamaktadır. Muller (1993) ise Prenatal Bağlanma (PB) kavramını, anne ve doğmamış bebeği arasında kurulan eşsiz, sevgi ve şefkat ilişkisi olarak tanımlamıştır.

Doğum sonu dönemde kurulmaya başlanan bağlanma davranışının temelleri gebelik dönemindeki anne-bebek bağlanması ile atılmaktadır (Yılmaz 2013). Bu dönemde güvenli bağlanmanın sağlanamaması durumunda bebeğin yaşamı fiziksel ve ruhsal yönden risk altına girebilmektedir (Çoban ve Saruhan 2005, Y1lmaz 2013, Elkin 2015, Mutlu ve ark. 2015, Höbek Akarsu ve ark. 2017, Baltacı ve Başer 2020). Prenatal dönemde kadınların vücudunda meydana gelen hormonal ve fiziksel değişiklikler, kadınları anneliğe hazırlamakta ve fetüse karşı bağlanma sürecini başlatmaktadır (Koptur Buldum ve Güner Emül 2017). Prenatal bağlanma bebek hareketlerinin ilk kez hissedilmesi veya bebeğin ultrason ile görüntülenmesiyle de ilişkilidir (Mehran ve ark. 2013).

Bağlanmanın oluştuğu ve geliştiği prenatal dönemde bağlanmayı etkileyen faktörleri tanımada, kadını anneliğe hazırlamada, anne ve fetüs arasında sevgi bağını başlatma ve sürdürmede, bağlanmayı destekleyici uygulamaları kullanmada, perinatal ve yenidoğan sağlı sonuçlarının iyileştirilmesinde ebe ve hemşirelerin önemli rol ve sorumlulukları bulunmaktadır (Koptur Buldum ve Güner Emül 2017). Ebe ve hemşireler bağlanmanın bir süreç olduğunu göz önüne alarak, aile-bebek etkileşimi ve kalitesini arttırmaya yönelik aileyi desteklemeli ve danışmanlık vermelidir. Prenatal dönemde güvenli bağlanmanın sağlanması, postnatal dönemde devam eden bağlanma davranışı için de önem arz etmektedir. Güvenli bağlanmanın sağlanamamasının bireyin ileriki yaşam dönemlerinde fiziksel ve ruhsal birtakım sorunlara yol açabileceği düşünüldüğünde, prenatal dönemde özellikle birinci 
basamakta hizmet veren ebe ve hemşirelerin anne-bebek bağlanmasını ve bunu etkileyen etmenleri dikkatle değerlendirmeleri gerekmektedir (Y1lmaz 2013, Elkin 2015). Kadın sağllğı alanında çalışan ebe ve hemşirelerin, prenatal bağlanmada sorun olan gebeleri etkili uygulamalar hakkında bilgilendirmeleri ve kendilerine en uygun yöntemi seçmelerine teşvik etmeleri önemlidir (Yılmaz 2013). Bu derleme ile literatür ışı̆̆ında prenatal bağlanmayı değerlendiren ölçüm araçlarının, etkileyen faktörlerin ve destekleyici kanıta dayalı uygulamaların sunulması amaçlanmıştır.

\section{Prenatal bağlanmanın değerlendirilmesinde kullanılan ölçüm araçları}

Anne ve fetüs arasındaki bağlanma düzeyini değerlendiren ölçme araçlarının geliştirilmesine 1970'li yıllarda başlanmıştır. Gebelerde anne-bebek bağlanmasını değerlendiren, Türkçe geçerlik ve güvenirliği yapılmış olan "Maternal-Fetal Bağlanma Ölçeği (MFBÖ)", "Prenatal Bağlanma Envanteri (PBE)", “Anne Doğum Öncesi Bağlanma Ölçeği (ADBÖ)”, "Prenatal Bağlanma Ölçeği (PBÖ)” bulunmaktadır. Kadın sağlığı alanında çalışan hemşire ve ebeler bu ölçüm araçlarını kullanarak gebelerde prenatal bağlanmayı değerlendirebilir ve risk altındaki kadınları erken dönemde belirleyebilirler.

Maternal-Fetal Bağlanma Ölçeği (MFBÖ), prenatal dönemde anne ile fetüs arasındaki bağlanmayı ölçmek için Cranley tarafından 1981 yılında geliştirilmiştir. MFBÖ, 24 sorudan oluşmakta ve ortalama puan ile değerlendirilmektedir. Gebenin ölçekten aldığı puanın artması bağlanma düzeyinin de arttığını göstermektedir. Ülkemizde ölçeğin geçerlikgüvenirlik çalışması Üstünsöz ve arkadaşları (2010) tarafından yapılmış ve Cronbach alpha değeri 0.82 bulunmuştur.

Prenatal Bağlanma Envanteri (PBE), doğum öncesi bağlanma düzeyini ölçmek için Muller tarafindan 1993 yılında geliştirilmiştir. Doğum öncesi bağlanma düzeyini ölçmeye yarayan literatürde en sık kullanılan ölçüm araçlarından biridir. Gebelik boyunca kadınların bebeğe ilişkin duygu, düşünce ve bağlanma düzeylerini belirlemek amaciyla geliştirilen ölçek, 21 maddeden oluşmaktadır. PBE'nden en az 21 en fazla 84 puan alınabilmektedir. Gebenin ölçekten aldığı puanın artması bağlanma düzeyinin de arttığını göstermektedir. Ülkemizde PBE'nin geçerlik-güvenirlik çalışması Yılmaz ve Beji (2013) tarafından yapılmış ve Cronbach alpha değeri 0.84 bulunmuştur. Ayrıca Doğum Öncesi Bağlanma Envanteri (DÖBE) adı ile Duyan ve arkadaşları tarafından 2013 yılında aynı ölçeğin Türkçe geçerlikgüvenirlik çalışması yapılmış ve Cronbach alpha değeri 0.90 olarak bulunmuştur.

Anne Doğum Öncesi Bağlanma Ölçeği (ADBÖ), gebelik döneminde maternalfetal bağlanma düzeyinin değerlendirilmesi amacıyla Condon tarafindan 1993 yilında geliştirilmiştir. Ölçek 19 madde ile birlikte, "bağlanma kalitesi” ve "bağlanmaya harcanan zaman” olmak üzere iki alt boyuttan oluşmaktadır. Gebenin ölçekten aldığı puanın artması bağlanma düzeyinin de arttığını göstermektedir. Ölçekten alınabilecek en düşük puan 19, en yüksek puan ise 95'tir. Ülkemizde ölçeğin geçerlik-güvenirlik çalışması Gölbaşı ve arkadaşları (2015) tarafindan yapılmış ve Cronbach alpha değeri 0.79 bulunmuştur. 
Prenatal Bağlanma Ölçeği (PBÖ), Türk kültürüne uygun prenatal bağlanma düzeyini ölçmek için Türkmen Çevik ve Kurnaz (2019) tarafindan geliştirilmiştir. Bu ölçek 33 madde ile birlikte ve "merak ve heyecan", "kabul ve coşku” ve "umut" olmak üzere üç alt boyuttan oluşmaktadır. Gebenin ölçekten aldığı puanın artması bağlanma düzeyinin de arttığını göstermektedir. Ölçekten alınabilecek en düşük puan 33, en yüksek puan ise 99'dur. PBÖ'nin iç tutarlılık katsayısı 0.94 olarak hesaplanmıştır.

\section{Prenatal bağlanma düzeyini etkileyen bazı faktörler}

Prenatal bağlanma bireysel ve çevresel birçok faktörden etkilenmektedir. Bunlar: yaş (Y1lmaz ve Kızılkaya Beji 2010, Alan Dikmen ve Çankaya 2018, Karabulutlu ve ark. 2020, Koç Özkan ve ark. 2020), eğitim durumu (Y1lmaz ve Kız1lkaya Beji 2010, Alan Dikmen ve Çankaya 2018, Topaç Tunçel ve Kahyaoğlu Süt 2019, Karabulutlu ve ark. 2020, Koç Özkan ve ark. 2020), çalışma durumu (Y1lmaz ve Kızılkaya Beji 2010, Elkin 2015, Topaç Tunçel ve Kahyaoğlu Süt 2019, Karabulutlu ve ark. 2020), aile tipi (Elkin 2015, Alan Dikmen ve Çankaya 2018, Karabulutlu ve ark. 2020), gelir durumu (Y1lmaz ve Kız1lkaya Beji 2010, Elkin 2015, Karabulutlu ve ark. 2020), evlilik süresi ve evlilik uyumu (Alan Dikmen ve Çankaya 2018, Karabulutlu ve ark. 2020, Küçükkaya ve ark. 2020), gebelik haftası (Elkin 2015, Alan Dikmen ve Çankaya, 2018, Topaç Tunçel ve Kahyaoğlu Süt 2019), gebeliğin istenme ve planlanma durumu (Y1lmaz ve Kızılkaya Beji 2010, Alan Dikmen ve Çankaya 2018, Karabulutlu ve ark. 2020, Küçükkaya ve ark. 2020), gebelik sayısı ve yaşayan çocuk sayısı (Y1lmaz ve Kızılkaya Beji 2010, Alan Dikmen ve Çankaya 2018, Karabulutlu ve ark. 2020, Koç Özkan ve ark. 2020), beden kitle indeksi (Alan Dikmen ve Çankaya 2018), psikososyal durum (Topaç Tunçel ve Kahyaoğlu Süt 2019, Özdemir ve ark. 2020), sosyal destek alma durumu (Erkal Aksoy ve ark. 2016, Alan Dikmen ve Çankaya 2018, Küçükaya ve ark. 2020), uyku süresi (Nacar ve Timur Taşhan 2019), prenatal bakım alma (Alan Dikmen ve Çankaya 2018, Karabulutlu ve ark. 2020) ve doğuma hazırlık sınıfina katılma durumu (Alan Dikmen ve Çankaya 2018)'dur (Tablo 1). Bu faktörlerin gebe ile en yakın etkileşimde olan ebe ve hemşireler tarafından tanınması önemlidir.

\section{Prenatal bağlanmayı destekleyici uygulamalar}

Kadın sağlığı alanında çalışan hemşire ve ebelerin öncelikle her gebeyi prenatal bağlanma bozukluğu riski açısından değerlendirmesi ve zayıf prenatal bağlanma tespit ettiği durumda buna yönelik müdahalelerde bulunması önemlidir. Makalenin bu bölümünde literatür 1̧̧ığında prenatal bağlanmayı destekleyen uygulamaları test eden araştırmalar sunulmuştur (Tablo 2).

\section{Fetal hareketleri sayma}

Ev ortamında gebe tarafindan fetal hareketlerin düzenli olarak sayılması ve kaydedilmesi uygulaması kolay, ucuz ve yararlı bir girişimdir. Literatür incelendiğinde maternal-fetal bağlanma üzerine etkisi en sık incelenen girişimsel çalışmaların fetal hareket sayımı eğitimi üzerine yapıldığı görülmüştür. Dört çalışmada fetal hareketleri sayma uygulamasının prenatal 
Tablo 1. Ülkemizde yapılan çalışma sonuçlarına göre prenatal bağlanmayı etkiyen anneye ait faktörler

\begin{tabular}{|c|c|}
\hline $\begin{array}{l}\text { Anneye ait } \\
\text { faktörler }\end{array}$ & renatal bağlanma düzeyine etkisi \\
\hline Yaş & $\begin{array}{l}\text { - } 31 \text { yaş üstü gebelerin prenatal bağlanma düzeyleri daha yüksektir (KoçÖzkan 2020) } \\
\text { - } 35 \text { yaş ve üstü gebelerin prenatal bağlanma düzeyleri daha düşüktür (Dereli Yılmaz ve Kızılkaya Beji 2010) } \\
\text { - } 40 \text { yaş ve üstü olan gebelerin prenatal bağlanma düzeyleri daha düşüktür (Karabulutlu ve ark. 2020) } \\
\text { - Gebelerin yaşı ile prenatal bağlanma düzeyleri arasında zayıf ve negatif yönlü ilişki bulunmuştur (Alan Dikmen } \\
\text { ve Çankaya 2018) } \\
\text { • Gebelerin yaşı ile prenatal bağlanma düzeyleri arasında bir ilişki bulunmamıştır (Elkin 2015) }\end{array}$ \\
\hline Eğitim durumu & $\begin{array}{l}\text { - Gebelerin eğitim durumu yükseldikçe, prenatal bağlanma düzeyleri artar (Kahyaoğlu Süt 2019) } \\
\text { • Illköğretim mezunu olan gebelerin prenatal bağlanma düzeyleri daha düşüktür (Alan Dikmen ve Çankaya 2018, } \\
\text { • Dereli Yılmaz ve Kızılkaya Beji 2010, Karabulutlu ve ark. 2020) } \\
\text { - Illköğretim mezunu kadınların prenatal bağlanma düzeyleri daha yüksektir (KoçÖzkan 2020) } \\
\text { - Gebelerin eğitim durumu ile prenatal bağlanma düzeyleri arasında bir ilişki bulunmamıştır (Elkin 2015) }\end{array}$ \\
\hline Çalışma durumu & $\begin{array}{l}\text { - Çalışmayan gebelerin prenatal bağlanma düzeyleri, çalışanlara göre daha düşüktür (Dereli YıImaz ve Kızılkaya } \\
\text { Beji 2010, Elkin 2015, Karabulutlu ve ark. 2020) } \\
\text { • Çalışan gebelerin prenatal bağlanma düzeyleri daha düşüktür (Kahyaoğlu Süt 2019) }\end{array}$ \\
\hline Aile tipi & $\begin{array}{l}\text { - Geniş aile yapısına sahip olan gebelerin prenatal bağlanma düzeyleri daha düşüktür (Alan Dikmen ve Çankaya } \\
\text { 2018, Karabulutlu ve ark. 2020) } \\
\text { • Gebelerin aile tipi ile prenatal bağlanma düzeyleri arasında bir ilişki bulunmuştur (Elkin 2015) }\end{array}$ \\
\hline Gelir durumu & $\begin{array}{l}\text { - Gelir düzeyi düşük olan gebelerin prenatal bağlanma düzeyleri daha düşüktür (Elkin 2015, Dereli Yılmaz ve } \\
\text { Kızılkaya Beji 2010, Karabulutlu ve ark. 2020) }\end{array}$ \\
\hline $\begin{array}{l}\text { Evlilik süresi ve } \\
\text { evlilik uyumu }\end{array}$ & $\begin{array}{l}\text { - Evlilik süresi } 11 \text { yıl ve üzeri olan gebelerin prenatal bağlanma düzeyleri daha düşüktür (Karabulutlu ve ark. 2020) } \\
\text { • Evlilik yılı ile prenatal bağlanma düzeyleri arasında zayıı, negatif yönlü ilişki bulunmuştur (Alan Dikmen ve } \\
\text { Çankaya 2018) } \\
\text { • İstemeyerek evlenen gebelerin prenatal bağlanma düzeyleri daha düşüktür (Alan Dikmen ve Çankaya 2018) } \\
\text { - Gebelerin çift uyumu arttıkça, prenatal bağlanma düzeyleri de artmaktadır (Küçükkaya ve ark. 2020). }\end{array}$ \\
\hline Gebelik haftası & $\begin{array}{l}\text { - Gebelik trimesteri arttıkça, gebelerin prenatal bağlanma düzeyleri de artmaktadır (Topaç Tunçel ve Kahyaoğlu } \\
\text { Süt 2019) } \\
\text { - Gebelik haftası } 26 \text { ve üzeri olanların prenatal bağlanma düzeyleri daha yüksektir (Elkin 2015) } \\
\text { - Gebelik haftası ile prenatal bağlanma düzeyleri arasında zayıf, negatif yönlü bir ilişki bulunmuştur (Alan } \\
\text { Dikmen ve Çankaya 2018) } \\
\text { - Gebelik ayının prenatal bağlanma düzeyine etkisi bulunmamıştır (Karabulutlu ve ark. 2020) }\end{array}$ \\
\hline $\begin{array}{l}\text { Gebeli } \\
\text { planla }\end{array}$ & $\begin{array}{l}\text { - Gebeliği planlı olan gebelerin prenatal bağlanma düzeyleri daha yüksektir (Dereli Yılmaz ve Kızılkaya Beji 2010, } \\
\text { Küçükkaya ve ark. 2020) } \\
\text { - Gebeliği sonlandırmayı düşünen gebelerin prenatal bağlanma düzeyleri daha düşüktür (Alan Dikmen ve } \\
\text { Çankaya 2018) } \\
\text { - Gebeliğin istenme durumu ile gebelerin prenatal bağlanma düzeyleri arasında bir ilişki bulunmamıştır (Elkin 2015) } \\
\text { - Gebeliği planlı olan ve gebeliği isteyenlerin prenatal bağlanma düzeyleri daha yüksektir (Karabulutlu ve ark. 2020) } \\
\text { - Gebeliği tedavi ile olanların prenatal bağlanma düzeyleri daha yüksektir (Karabulutlu ve ark. 2020) }\end{array}$ \\
\hline $\begin{array}{l}\text { Gebelik sayısı ve } \\
\text { yaşayan çocuk sayısı }\end{array}$ & $\begin{array}{l}\text { - Multipar kadınların prenatal bağlanma düzeyleri daha yüksektir (Dereli Yılmaz ve Kızılkaya Beji 2010) } \\
\text { - Gebelik sayısı } 3 \text { ve üzeri olan kadınların prenatal bağlanma düzeyleri daha yüksektir (KoçÖzkan 2020) } \\
\text { - Yaşayan çocuk sayısı ve ile prenatal bağlanma düzeyleri arasında zayıf, negatif yönlü bir ilişki bulunmuştur (Alan } \\
\text { Dikmen ve Çankaya 2018) } \\
\text { - Daha önce hiç çocuğu olmayan yada bir çocuğu olan gebelerin prenatal bağlanma düzeyleri daha yüksektir } \\
\text { (Karabulutlu ve ark. 2020) } \\
\text { - Gebelik sayısı ve yaşayan çocuk sayısı ile prenatal bağlanma düzeyi arasında bir ilişki bulunmamıştır (Elkin 2015) }\end{array}$ \\
\hline
\end{tabular}


Tablo 1. Devamı

\begin{tabular}{|c|c|}
\hline $\begin{array}{l}\text { Anneye ait } \\
\text { faktörler }\end{array}$ & Prenatal bağlanma düzeyine etkisi \\
\hline Beden Kitle İndeksi & $\begin{array}{l}\text { - Obez gebelerin prenatal bağlanma düzeyi, normal ve pre-obez gebelere göre daha düşüktür (Alan Dikmen ve } \\
\text { Çankaya 2018) }\end{array}$ \\
\hline Doğum korkusu & - Gebelerde algılanan doğum korkusu ile prenatal bağlanma düzeyi arasında ilişki bulunmamıştır (Sade ve ark. 2020) \\
\hline Uyku süresi & $\begin{array}{l}\text { - Yedi saatten daha az uyuyan gebelerin prenatal bağlanma düzeyleri, daha fazla uyuyanlara göre daha yüksektir } \\
\text { (Nacar ve Timur Taşhan 2019) }\end{array}$ \\
\hline Psikososyal durum & $\begin{array}{l}\text { - Gebelerin Beck Anksiyete Ölçeğinden aldıkları puanlar ile PBE puan ortalamaları arasında negatif yönde orta } \\
\text { düzeyde bir ilişki bulunmuştur (Özdemir ve ark 2020). } \\
\text { - 1. trimester gebelerde prenatal distres düzeyi arttıkça doğum öncesi bebeğe bağlanma düzeyi de artmakta, } 3 \text {. } \\
\text { trimesterde depresyon düzeyi arttıkça doğum öncesi bağlanma azalmaktadır. Gebelik sürecinde anksiyete düzeyi } \\
\text { arttıkça doğum öncesi bağlanma artmaktadır (Topaç Tunçel ve Kahyaoğlu Süt 2019) }\end{array}$ \\
\hline $\begin{array}{l}\text { Sosyal destek alma } \\
\text { durumu }\end{array}$ & $\begin{array}{l}\text { - Gebelerin prenatal bağlanma düzeyleri ile Çok Boyutlu Algılanan Sosyal Destek Ölçeği puan ortalamaları } \\
\text { arasında pozitif yönde bir ilişki bulunmuştur (Erkal Aksoy ve ark. 2016) } \\
\text { - Duygusal ya da fiziksel yönden destek alan gebelerin prenatal bağlanma düzeyleri daha yüksektir (Küçükaya ve } \\
\text { ark. 2020) } \\
\text { - Gebeliği aileye ilk haber verme zamanı ve prenatal bağlanma düzeyleri arasında zayıf, negatif yönlü ilişki } \\
\text { bulunmuştur (Alan Dikmen ve Çankaya 2018) }\end{array}$ \\
\hline Prenatal bakım alma & $\begin{array}{l}\text { - Gebelikte sağlık problemi yaşayan gebelerin prenatal bağlanma düzeyleri daha düşüktür (Alan Dikmen ve } \\
\text { Çankaya 2018) } \\
\text { - Gebeliği süresince az kontrole giden, eğitim almayan ve gebelik boyunca gerekli testleri yaptırmayanların, } \\
\text { prenatal bağlanma düzeyleri daha düşüktür (Karabulutlu ve ark. 2020) } \\
\text { • Doğuma hazırlık sınıfına katılmayan gebelerin prenatal bağlanma düzeyleri daha düşüktür (Alan Dikmen ve } \\
\text { Çankaya 2018) }\end{array}$ \\
\hline
\end{tabular}

bağlanmayı desteklediği bulunurken, iki çalışmada etkili olmadığı bulunmuştur. Mikhail ve arkadaşları (1991), Rincy ve Nalini (2014), Güney ve Uçar (2019) ve Demirkan ve arkadaşları (2020) çalı̧̧malarında fetal hareket sayımı uygulamasının maternal-fetal bağlanmaya etkisini incelemişlerdir. $\mathrm{Bu}$ araştırmadaki girişim grubundaki gebelere fetal hareket sayımı eğitimi verildikten sonra günlük fetal hareketleri saymaları istenmiştir. Kontrol grubundaki gebelere standart doğum öncesi bakım verilmiştir. Müdahale sonunda girişim grubundaki gebelerin maternal-fetal bağlanma puan ortalamaları, kontrol grubundaki gebelere göre istatistiksel olarak anlamlı düzeyde daha yüksek bulunmuştur. Öte yandan Saastad ve arkadaşları (2011), Delaram ve arkadaşlarının (2018) çalışmalarında ise fetal hareket sayımı eğitiminin gebelerin prenatal bağlanma düzeylerini desteklemede etkili olmadığı ortaya konmuştur.

\section{Leopold manevrasi uygulaması}

Son trimesterde leopold manevrası uygulamasının gebelerde prenatal bağlanma düzeyini desteklediği iki çalı̧̧mada belirlenmiştir. Celik ve Ergin (2020) ve Nishikawa ve Sakakibara'nin (2013) çalışmalarında girişim grubundaki gebelere leopold manevraları uygulanırken, kontrol grubundaki gebelere rutin prenatal bakım verilmiştir. Müdahale sonunda girişim grubundaki gebelerin prenatal bağlanma düzeyleri, kontrol grubundaki gebelere göre istatistiksel olarak anlamlı düzeyde daha yüksek bulunmuştur. 


\section{Eğitim ve danışmanlık}

Gebelere verilen eğitim ve danışmanlık yaklaşımının, sağlıklı şekilde devam eden gebeliklerde prenatal bağlanmayı desteklemenin yanı sıra, bebek kaybı ya da şiddet öyküsü olan, istenmeyen ya da planlanmayan gebeliği olan gebelerde de prenatal bağlanmayı desteklediği çalışmalarla ortaya konmuştur. Marzouk ve arkadaşları (2015), Abasi ve arkadaşları (2013) ve Akbarzadeh ve arkadaşlarının (2017) çalışmalarında üçüncü trimesterdeki gebelere maternal-fetal bağlanma becerileri konusunda verilen eğitimin prenatal bağlanmayı arttırdığ1 saptanmıştır. Planlanmamış ve istenmeyen gebeliklerde danışmanlık hizmetinin maternal-fetal bağlanma düzeyinin iyileştirilmesinde etkili olduğu Ekrami ve arkadaşları (2019), Jangjoo ve arkadaşlarının (2019) çalışmalarında ortaya konmuştur. Bu sebeple ebe ve hemşirelerin istenmeyen gebeliklerin önlenmesi amacıyla etkin bir aile planlaması danışmanlığı hizmeti vermesi önerilebilir. Baghdari ve arkadaşlarının (2016) çalışmasında bebek kaybı öyküsü olan gebelere verilen gebeliğe uyum eğitimin maternal-fetal bağlanmayı arttırdığı̆, Khalili ve arkadaşlarının (2020) çalışmasında ise eşi tarafindan şiddete maruz kalan gebelerde destekleyici-eğitici müdahalenin maternal-fetal bağlanmayı arttırdığ ortaya konmuştur.

\section{Baba eğitimi}

Babalara verilen bağlanma davranış ve beceri eğitiminin prenatal bağlanma üzerine etkisini inceleyen yalnızca bir çalışma bulunmuştur. Akbarzade ve arkadaşlarının (2014), girişim grubundaki babalara bağlanma davranış ve beceri eğitimi verilirken, kontrol grubundaki gebelere rutin gebelik bakımı verilmiştir. Girişim grubu ile kontrol grubu arasında, müdahaleden önceki ve bir ay sonraki ortalama bağlanma puanları açısından anlamlı bir fark olduğu ortaya çıkmıştır. Bu nedenle prenatal bakım programlarına babaların da katılımının desteklenmesinin önemli olduğu düşünülmektedir.

\section{Müzik}

Müzik dinletmenin prenatal bağlanmaya etkisini inceleyen iki çalışma bulunmuş ancak her ikisinde de müzik dinlemenin prenatal bağlanmayı desteklemede etkili olmadığı ortaya çıkmıştır. Chang ve arkadaşlarının (2015) çalışmasında gebelere müzik dinletilmesi uygulamasının maternal-fetal bağlanma düzeyini arttırmada etkili olmadığ 1 bulunmuştur. Ayrıca Shin ve Kim (2011) çalışmalarında transvajinal ultrason sırasında uygulanan müzik terapisinin maternal-fetal bağlanma düzeyine etkisini incelemişlerdir. $\mathrm{Bu}$ araştırmadaki girişim grubundaki gebelere transvajinal ultrasonografi sırasında rutin prenatal bakım ve tek seans müzik terapisi uygulanırken, kontrol grubundaki gebelere ise rutin prenatal bakım verilmiştir. Girişim ve kontrol grubundaki gebelerin maternal-fetal bağlanma düzeyleri arasında istatistiksel olarak anlamlı bir fark bulunmamıştır. Bu iki çalışmanın sonuçlarına göre, müzik dinletmeye yönelik daha fazla araştırma yapılması önerilmektedir. 
Tablo 2. Prenatal bağlanmayı destekleyen uygulamaları araştıran çalışmaların incelenmesi

\section{Yazar, yıl, ülke Yöntem Örneklem}

Abasi ve ark.2013, İran $\quad$ Yarı deneysel $\quad \begin{aligned} & \text { GG: Haftada bir kez, iki saat süren, toplamda dört seans, maternal-fetal bağlanma davranışı eğitimi } \\ & (n=40)\end{aligned}$
KG: Standart doğum öncesi bakım $(n=43)$

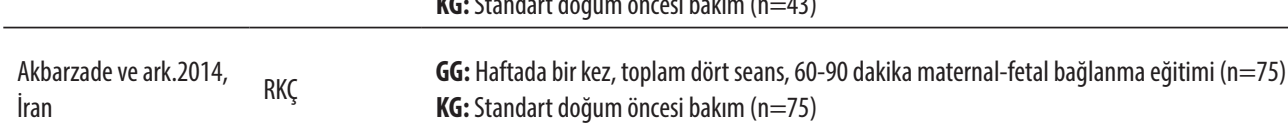

\begin{tabular}{|c|c|c|}
\hline $\begin{array}{l}\text { Akbarzadeh ve } \\
\text { ark.2017, İran }\end{array}$ & Deneysel & $\begin{array}{l}\text { GG: Altı hafta süresince, haftada bir kez, } 90 \text { dakika süren, BASNEF modeline temellendirilmiş } \\
\text { eğitim ( } n=50) \\
\text { KG: Standart doğum öncesi eğitim }(n=50)\end{array}$ \\
\hline $\begin{array}{l}\text { Alhusen ve ark.2021, } \\
\text { Amerika }\end{array}$ & RKÇ & $\begin{array}{l}\text { GG: Altı hafta süresince, haftada iki saat, grup temelli Bilişsel Davranış̧̧ı terapi girişimi }(n=30) \\
\text { KG: Standart doğum öncesi bakım }(n=30)\end{array}$ \\
\hline $\begin{array}{l}\text { Baghdari ve ark.2016, } \\
\text { İran }\end{array}$ & Deneysel & $\begin{array}{l}\text { GG: Standart doğum öncesi eğitim ve dört seanslık gebeliğe uyum eğitim programı }(n=30) \\
\text { KG: Standart doğum öncesi eğitim }(n=30)\end{array}$ \\
\hline $\begin{array}{l}\text { Bellieni ve ark.2007, } \\
\text { İtalya }\end{array}$ & Deneysel & $\begin{array}{l}\text { GG: Beş seans ve bir saat süren doğum öncesi eğitim kursu }(n=36) \\
\text { KG: Herhangi bir girişim uygulanmadı }(n=41)\end{array}$ \\
\hline $\begin{array}{l}\text { Celik ve Ergin, 2020, } \\
\text { Türkiye }\end{array}$ & RKÇ & $\begin{array}{l}\text { GG: I. ve II. Leopold manevraları ile yapılan hemşirelik uygulaması }(n=50) \\
\text { KG: Standart doğum öncesi bakım }(n=50)\end{array}$ \\
\hline $\begin{array}{l}\text { Chang ve ark.2004, } \\
\text { Güney Kore }\end{array}$ & Deneysel & Doğuma hazırlık sınıfı $(n=49)$ \\
\hline $\begin{array}{l}\text { Chang ve ark. 2015, } \\
\text { Tayvan }\end{array}$ & RKÇ & $\begin{array}{l}\text { GG: Müzik dinletme ve standart doğum öncesi bakım ( } n=145) \\
\text { KG: Standart doğum öncesi bakım ( } n=151)\end{array}$ \\
\hline $\begin{array}{l}\text { Çıtak Bilgin ve ark. } \\
\text { 2020, Türkiye }\end{array}$ & Deneysel & $\begin{array}{l}\text { GG: Beş hafta süresince, üç saat, haftada bir kez doğum eğitimi }(\mathrm{n}=90) \\
\text { KG: Rutin prenatal izlem ( } \mathrm{n}=83 \text { ) }\end{array}$ \\
\hline $\begin{array}{l}\text { Delaram ve ark.2018, } \\
\text { İran }\end{array}$ & RKÇ & $\begin{array}{l}\text { GG: Fetal hareket takibi eğitimi ve uygulaması }(\mathrm{n}=104) \\
\text { KG: Standart doğum öncesi bakım }(\mathrm{n}=104)\end{array}$ \\
\hline $\begin{array}{l}\text { Demirkan ve ark. 2020, } \\
\text { Türkiye }\end{array}$ & Deneysel & $\begin{array}{l}\text { GG: Fetal hareket takibi eğitimi }(n=35) \\
\text { KG: Standart doğum öncesi bakım ( } n=35)\end{array}$ \\
\hline Ekrami ve ark.2019, İran & RKÇ & $\begin{array}{l}\text { GG: Altı hafta süreyle, haftada bir kez bireysel ya da grup danışmanlığı }(n=40) \\
\text { KG: Standart doğum öncesi bakım }(n=40)\end{array}$ \\
\hline Gheibi ve ark.2020, Iran & RKÇ & $\begin{array}{l}\text { GG: Standart doğum öncesi bakım ile birlikte farkındalık temelli bir doğum ve ebeveynlik programı } \\
\text { ( } \mathrm{n}=18) \\
\text { KG: Standart doğum öncesi bakım }(\mathrm{n}=20)\end{array}$ \\
\hline $\begin{array}{l}\text { Güney ve Uçar 2019, } \\
\text { Türkiye }\end{array}$ & RKÇ & $\begin{array}{l}\text { GG: Fetal hareket takibi eğitimi ve uygulaması }(\mathrm{n}=55) \\
\text { KG: Standart doğum öncesi bakım }(\mathrm{n}=55)\end{array}$ \\
\hline $\begin{array}{l}\text { Höbek Akarsu ve } \\
\text { Rathfisch 2018, Türkiye }\end{array}$ & RKÇ & $\begin{array}{l}\text { GG: Sekiz hafta süreyle, haftada iki gün, } 40 \text { dakika yoga uygulaması ve standart doğum öncesi } \\
\text { bakım ( } n=31 \text { ) } \\
\text { KG: Standart doğum öncesi bakım ( } n=32)\end{array}$ \\
\hline $\begin{array}{l}\text { Jangjo0 ve ark. 2019, } \\
\text { İran }\end{array}$ & RKÇ & $\begin{array}{l}\text { GG: Dört hafta süreyle, toplam dört seans grup danışmanlığı }(n=40) \\
\text { KG: Standart doğum öncesi bakım }(n=40)\end{array}$ \\
\hline $\begin{array}{l}\text { Kartal ve Karaman, } \\
\text { 2018, Türkiye }\end{array}$ & Deneysel & Doğuma hazırlık sınıfı $(\mathrm{n}=44)$ \\
\hline
\end{tabular}




\section{Ölçüm Sonuçlar}

aracl

MFBÖ Girişim $(3,96 \pm 0,38)$ ve kontrol $(3,42 \pm 0,41)$ grubundaki gebelerin bağlanma puanları açısından istatistiksel olarak anlamlı bir fark olduğu bulunmuştur $(p<0,001)$,

GG'nun ortalama prenatal bağlanma puan ortalaması müdahale öncesi $55,98 \pm 6,99$ ve sonrası $61,90 \pm 5,41$ idi, GG ile KG

MFBÖ arasında, müdahaleden bir ay sonra ortalama prenatal bağlanma puanları açııından istatistiksel olarak anlamlı bir fark bulunmuştur $(p<0,001)$,

MFВ0̈ Girişim $(4,63 \pm 30,75)$ ve kontrol $(3,19 \pm 22,20)$ gruplarının maternal-fetal bağlanma düzeylerinde istatistiksel olarak anlamlı düzeyde bir fark bulunmuştur $(p<0,001)$,

MFBÖ Müdahale sonunda, GG'ndaki gebelerin prenatal bağlanma düzeylerinde 12,6 puanlık bir artış ölçülürken, KG'nda ise 4,6 puanlık bir artış ölçülmüş̧ür,

МЕВӦ Girişim $(77,57 \pm 7,23)$ ve kontrol $(61,53 \pm 2,62)$ grubundaki gebelerin maternal-fetal bağlanma düzeylerinde istatistiksel olarak anlamlı bir fark bulunmuştur $(p=0,001)$,

PBE Doğum öncesi eğitime katılan GG'ndaki $(65,5 \pm 6,9)$ gebelerin prenatal bağlanma düzeyleri, KG'sindeki $(59,9 \pm 6,1)$ gebelere göre istatistiksel olarak anlamlı düzeyde daha yüksek bulunmuştur $(p<0,05)$,

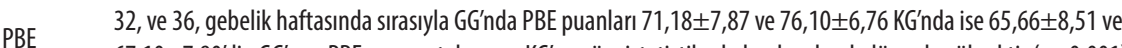
$67,10 \pm 7,80$ 'dir, GG'nun PBE puan ortalaması, KG'na göre istatistiksel olarak anlamlı düzeyde yüksektir $(p=0,001)$,

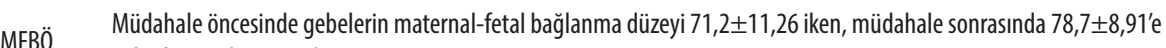
yükselmiştir $(p<0,001)$,

M-MFBÖ Girişim $(100,96 \pm 20,47)$ ve kontrol $(95,60 \pm 22,83)$ gruplarında maternal-fetal bağlanma düzeylerinde istatistiksel olarak anlamlı bir fark bulunmamıştır $(p>0,05)$,

GG'nda prenatal bağlanma düzeyi istatistiksel olarak anlamlı düzeyde artmıştır $(p<0,001)$, Müdahale sonrasında girişim $(71,7 \pm 8,9)$ ve kontrol $(70,1 \pm 8,6)$ gruplarının puanlarında istatistiksel olarak anlamlı bir artış olmamıştır,

PBE Girişim $(93,75 \pm 7,59)$ ve kontrol $(92,78 \pm 9,90)$ gruplarının prenatal bağlanma düzeyleri arasında istatistiksel olarak anlamlı bir fark bulunmamışıı $(p=0,433)$,

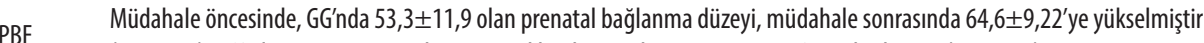

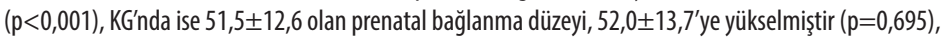

MFBÖ Dört hafta sonra gebelerin maternal-fetal bağlanma düzeyleri ölçülmüş, girişim $(96,6 \pm 9,3)$ ve kontrol $(76,5 \pm 6,4)$ gruplarının maternal-fetal bağlanma düzeyleri arasında istatistiksel olarak anlamlı bir fark bulunmuştur $(p<0,001)$,

MFBÖ GG'nun $(95,39 \pm 7,20)$ maternal-fetal bağlanma düzeyi, kontrol $(83,60 \pm 6,93)$ grubuna göre istatistiksel olarak anlamlı düzeyde daha yüksek bulunmuştur $(p<0,001)$,

ADBÖ Girişim $(78,41 \pm 6,65)$ ve kontrol $(72,25 \pm 7,16)$ gruplarının maternal-fetal bağlanma skorları arasında istatistiksel olarak anlaml bir fark bulunmuştur $(p<0,001)$,

GG'ndaki gebeler sekiz hafta süreyle, haftada iki gün, 40 dakika yoga yaparken, KG'ndaki gebelere standart doğum öncesi

PBE bakım verilmiştir, Müdahale sonunda GG'nun $(67,6 \pm 8,7)$ prenatal bağlanma düzeyi, kontrol $(61,9 \pm 11,4)$ grubuna göre anlamlı derecede yüksek bulunmuştur $(p=0,031)$,

MFBÖ Girişim $(104,43 \pm 22,51)$ ve kontrol $(64,79 \pm 12,86)$ gruplarının maternal-fetal bağlanma düzeyleri arasında istatistiksel olarak anlamlı bir fark bulunmuştur $(\mathrm{p}<0,001)$, 
Tablo 2. Devamı

\begin{tabular}{|c|c|c|}
\hline Yazar, yıl, ülke & Yöntem & Örneklem \\
\hline Khalili ve ark.2020, İran & RKÇ & $\begin{array}{l}\text { GG: Dört seans, bireysel destekleyici-eğitici müdahale }(n=50) \\
\text { KG: Standart doğum öncesi bakım }(n=50)\end{array}$ \\
\hline $\begin{array}{l}\text { Kim ve Gim 2019, } \\
\text { Güney Kore }\end{array}$ & Deneysel & $\begin{array}{l}\text { GG: İyilik ve şefkat meditasyon programı }(n=27) \\
\text { KAG: Yoga uygulaması }(n=29) \\
\text { KG: Herhangi bir girişim uygulanmadı }(n=27)\end{array}$ \\
\hline $\begin{array}{l}\text { Kordi ve ark 2016, } \\
\text { İran }\end{array}$ & Deneysel & $\begin{array}{l}\text { GG: Rehberli imgeleme eğitimi ve uygulaması }(\mathrm{n}=35) \\
\text { KG: Standart doğum öncesi bakım }(\mathrm{n}=32)\end{array}$ \\
\hline $\begin{array}{l}\text { Marzouk ve Nabil 2015, } \\
\text { Mısır }\end{array}$ & Deneysel & $\begin{array}{l}\text { GG: Maternal-fetal bağlanma becerisi eğitimi }(n=40) \\
\text { KG: Standart doğum öncesi bakım }(n=40)\end{array}$ \\
\hline $\begin{array}{l}\text { Mikhail ve ark.1991, } \\
\text { Amerika }\end{array}$ & Deneysel & $\begin{array}{l}\text { GG: Bir ay süresince fetal hareket sayımı }(n=125) \\
\text { KG: Herhangi bir girişism uygulanmadı }(n=88)\end{array}$ \\
\hline $\begin{array}{l}\text { Mojahed ve ark.2019, } \\
\text { İran }\end{array}$ & Deneysel & $\begin{array}{l}\text { GG: Altı hafta süresince, } 90 \text { dakika süren bilişsel-davranışçı yaklaşımla ebelik danışmanlığı }(\mathrm{n}=30) \\
\text { KG: Doğuma hazırlık sınıfında verilen prenatal bakım ve eğitim }(\mathrm{n}=30)\end{array}$ \\
\hline $\begin{array}{l}\text { Mokaberian ve } \\
\text { ark.2021, İran }\end{array}$ & Deneysel & $\begin{array}{l}\text { GG: Sekiz hafta süresince, haftada iki kez, } 30 \text { dakikalık hayal etme temelli gevşeme tekniği ile } \\
\text { progresif kas gevşetme uygulaması }(n=30) \\
\text { KG: Herhangi bir girişim uygulanmadı }(n=30)\end{array}$ \\
\hline $\begin{array}{l}\text { Nishikawa ve } \\
\text { Sakakibara 2013, } \\
\text { Japonya }\end{array}$ & Deneysel & $\begin{array}{l}\text { GG: Gebe bilgilendirme sınıfı ve abdominal palpasyon ile Leopold manevraları uygulaması }(\mathrm{n}=35) \\
\text { KG: Gebe bilgilendirme sınıfı uygulaması }(\mathrm{n}=30)\end{array}$ \\
\hline $\begin{array}{l}\text { Rincy ve Nalini 2014, } \\
\text { Hindistan }\end{array}$ & Deneysel & $\begin{array}{l}\text { GG: Standart doğum öncesi bakım ve } 14 \text { gün boyunca, günde iki kez fetal hareket takibi }(n=50) \\
\text { KG: Standart doğum öncesi bakım }(n=50)\end{array}$ \\
\hline $\begin{array}{l}\text { Saastad ve ark.2011, } \\
\text { Norveç }\end{array}$ & RKÇ & $\begin{array}{l}\text { GG: Fetal hareket takibi eğitimi ve uygulaması }(n=478) \\
\text { KG: Standart doğum öncesi bakım ( } n=473)\end{array}$ \\
\hline Salehi ve ark.2017, İran & RKÇ & $\begin{array}{l}\text { GG: Fetal hareket takibi eğitimi ve uygulaması }(n=23) \\
\text { KG: Standart doğum öncesi bakım }(n=29)\end{array}$ \\
\hline Shin ve Kim, 2011, Kore & Deneysel & $\begin{array}{l}\text { GG: Standart doğum öncesi bakım ve } 30 \text { dakikalık tek seans müzik terapisi }(n=117) \\
\text { KG: Standart doğum öncesi bakım ( } n=116)\end{array}$ \\
\hline Toosi ve ark.2014, İran & Deneysel & $\begin{array}{l}\text { GG: Standart doğum öncesi bakım ve haftada bir kez, } 90 \text { dakika süren, dört seans gevşeme eğitimi } \\
\text { ( } \mathrm{n}=42 \text { ) } \\
\text { KG: Standart doğum öncesi bakım ( } \mathrm{n}=42 \text { ) }\end{array}$ \\
\hline Toosi ve ark.2017, İran & Deneysel & $\begin{array}{l}\text { GG: Standart doğum öncesi bakım ve haftada bir kez, en az } 90 \text { dakika süren, dört seans gevşeme } \\
\text { eğitimi ( } n=40) \\
\text { KG: Standart doğum öncesi bakım ( } n=40)\end{array}$ \\
\hline
\end{tabular}

GG: Girişim grubu, KG: Kontrol grubu, KAG: Karşılaştırma grubu, ADBÖ: Anne doğum öncesi bağlanma ölçeği, MFBÖ: Maternal-fetal bağlanma ölçeği, M- MFBÖ: Modifiye edilm

\section{Gevşeme egzersizi ve rehberli imgeleme}

Düşük maliyetli ve non-farmakolojik bir yöntem olan hayal etme temelli gevşeme tekniği ile progresif kas gevşetme uygulamasının maternal-fetal bağlanmayı desteklemede etkili olduğu çalışmalarla gösterilmiştir. Toosi ve arkadaşlarının (2014, 2017) çalışmalarında gebelere verilen eğitiminin maternal-fetal bağlanma üzerine etkisini incelemişlerdir. 
Ölçüm Sonuçlar

aracı

MFBÖ Girişim $(80,36 \pm 6,75)$ ve kontrol $(65,50 \pm 6,78)$ gruplarının maternal-fetal bağlanma düzeylerinde istatistiksel olarak anlamlı fark bulunmuştur $(p=0,0001)$.

İyilik ve şefkat meditasyon programına alınan gebeler ile yoga ve kontrol gruplarına alınan gebelerin prenatal bağlanma

MFBÖ düzeylerinde istatistiksel olarak anlamlı fark bulunmuştur $(p<0,001)$, İyilik ve şefkat meditasyon programına katılan gebelerin prenatal bağlanma düzeyleri, diğer iki gruba göre istatistiksel olarak anlamlı düzeyde daha fazla artmıştır,

MFBÖ Girişim $(94,26 \pm 6,7)$ ve kontrol $(90,22 \pm 9,5)$ gruplarının maternal-fetal bağlanma skorları arasında istatistiksel olarak anlamlı bir fark bulunmuştur $(p=0,046)$,

GG'nda eğitim öncesinde $61,6 \pm 5,9$ olan MFBÖ toplam puan ortalaması, 32. ve 34 . gebelik haftalarında sırasılyla $68,5 \pm 6,8$ ve

MFBÖ $\quad 69,6 \pm 5,9^{\prime}$ a yükselmiştir $(p<0,001)$,

KG'nun MFBÖ toplam puan ortalamasında istatistiksel olarak anlamlı bir fark olmamıştır $(p=0,379)$,

MFBÖ Müdahale sonrası, GG'ndaki gebelerin maternal-fetal bağlanma düzeyi, KG'na göre istatistiksel olarak anlamlı düzeyde yüksek bulunmuştur $(p<0,05)$,

Müdahaleden sonra, girişim $(99,8 \pm 5,64)$ ve kontrol $(90,9 \pm 2,15)$ gruplarının prenatal bağlanma düzeyleri arasında istatistikse olarak anlamlı fark bulunmuştur ( $p<0,001$ ), Ayrıca müdahale sonrasında GG'ndaki gebelerde maternal-fetal bağlanma düzeyi 13,53 puan artmıştır $(p<0,001)$,

Müdahale sonunda, girişim $(97,4 \pm 60,04)$ ve kontrol $(86,3 \pm 13,72)$ gruplarının maternal-fetal bağlanma düzeylerinde

MFBÖ istatistiksel olarak anlamlı fark bulunmuştur $(p=0,0001)$,

PBE GG ve KG'ndaki gebelerde prenatal bağlanma düzeyi önemli ölçüde yükselse de bu artış GG'nda KG'na kıyasla daha fazladır,

PBE

Girişim $(64,38 \pm 7,53)$ ve kontrol $(49,29 \pm 11,46)$ gruplarının maternal-fetal bağlanma skorları arasında istatistiksel olarak anlamlı bir fark bulunmuştur $(p=0,000)$,

PBE Girişim $(59,54 \pm 9,39)$ ve kontrol $(59,43 \pm 9,35)$ gruplarının maternal-fetal bağlanma skorları arasında istatistiksel olarak anlamlı bir fark bulunmamıştır $(p=0,747)$,

MFBÖ Girişim $(96,30 \pm 10,81)$ ve kontrol $(88,64 \pm 10,31)$ grubunun maternal-fetal bağlanma düzeyleri arasında istatistiksel olarak anlamlı bir fark bulunmuştur $(\mathrm{p}<0,001)$,

MFBÖ Girişim $(64,81 \pm 11,51)$ ve kontrol $(65,73 \pm 13,08)$ grubunun maternal-fetal bağlanma düzeyleri arasında istatiksel olarak anlamlı bir fark bulunmamıştır $(p=0,659)$,

Girişim $(63,6 \pm 4,3)$ ve kontrol $(61,1 \pm 51)$ grubundaki gebelerin maternal-fetal bağlanma düzeyleri arasında istatistiksel olarak

МFBÖ anlamlı bir fark bulunmuştur $(p=0,017)$,

Girişim $(92,0 \pm 10,8)$ ve kontrol $(74,0 \pm 13,8)$
MFÖlamlı bir fark bulunmuştur $(\mathrm{p}<0,001)$,

ş Maternal-fetal bağlanma ölçeği, PBE: Prenatal bağlanma envanteri

$\mathrm{Bu}$ araştırmadaki girişim grubundaki gebelere standart doğum öncesi bakımın yanı sıra gevşeme eğitimi verilirken, kontrol grubundaki gebelere ise standart doğum öncesi bakım verilmiştir. Müdahale sonunda, girişim grubundaki gebelerin maternal-fetal bağlanma düzeyleri, kontrol grubundaki gebelere göre istatistiksel olarak anlamlı düzeyde daha yüksek bulunmuştur. Kordi ve arkadaşlarının (2016) çalışmasında ise planlanmamış gebeliği olan 
kadınlara verilen rehberli hayal etme egzersizi eğitimi ve uygulamasının; Mokaberian ve arkadaşlarının (2021) çalışmasında ise hayal etme temelli gevşeme tekniği ile progresif kas gevşetme uygulamasının istenmeyen gebeliği olan kadınlarda maternal-fetal bağlanmayı arttırmada etkili olduğu ortaya konmuştur.

\section{Bilişsel davranış̧̧ı terapiler}

Bilişsel davranış̧̧ı terapiler özellikle yüksek riskli gebeliklerde prenatal bağlanmayı desteklemede etkili olduğu üç çalışmada gösterilmiştir. Azogh ve arkadaşları (2018) ölü doğum öyküsü olan gebelerde, Mojahed ve arkadaşları (2019) kürtaj öyküsü olan gebelerde bilişsel davranış̧̧ı terapinin maternal-fetal bağlanmayı arttırdığını belirlemiştir. Alhusen ve arkadaşları (2021) ise orta ve şiddetli derecede depresif semptomu olan bir grup gebeye uygulanan bilişsel davranış̧ı terapi girişiminin prenatal bağlanma düzeyini desteklemede etkili olduğunu saptamıştır. Kadın sağlığı alanında çalışan hemşire ve ebeler depresyon ve anksiyete gibi psikiyatrik rahatsızlıkların bağlanmayı etkilediğini göz önünde bulundurarak, gebe kalmayı planlayan depresif semptomlar ve diğer psikiyatrik sorunlar bakımından risk altında olan gebeleri psikiyatriste yönlendirilmesi son derece önemlidir.

\section{Doğuma hazırlık eğitimi}

Doğuma hazırlık eğitiminin gebelerin maternal-fetal bağlanmayı desteklediği dört çalışmada gösterilmiştir. Bellieni ve arkadaşları (2007) ve Chang ve arkadaşlarının (2004) çalışmalarında doğum öncesi eğitim kurslarına katılan gebelerin prenatal bağlanma düzeylerinin, standart bakım alan gebelere göre istatistiksel olarak anlamlı düzeyde arttığ 1 gösterilmiştir. Ülkemizde yürütülmüş olan Kartal ve Karaman (2018) ve Çıtak Bilgin ve arkadaşlarının (2020) çalışmalarında doğuma hazırlık eğitiminin gebelerin prenatal bağlanma düzeylerini arttırdığı ortaya konmuştur.

\section{Meditasyon ve yoga}

Literatürde meditasyon ve yoga uygulamasının prenatal bağlanmayı arttırdığ konmuştur. Gheibi ve arkadaşlarının (2020) çalışmasında, standart doğum öncesi bakım ile birlikte farkındalık temelli doğum ve ebeveynlik programına alınan gebelerin prenatal bağlanma düzeylerinin arttığı saptanmıştır. Kim ve Gim (2019) çalışmalarında girişim grubundaki gebeleri iyilik ve şefkat meditasyon programına, karşılaştırma grubundaki gebeleri yoga programına almıştır. Kontrol grubundaki gebelere ise herhangi bir girişim uygulamamıştır. İyilik ve şefkat meditasyon programına katılan gebelerin prenatal bağlanma düzeylerinde, diğer iki gruba göre istatistiksel olarak anlamlı düzeyde daha fazla artmıştır. Ülkemizde ise Höbek Akarsu ve Rathfisch'in (2018) yaptığı çalışmada, gebelikte yapılan yoganın prenatal bağlanmayı artırmada etkili bir yöntem olduğunu göstermiştir.

\section{Sonuç}

Mevcut literatürün incelenmesi ile fetal hareket sayımı, leopold manevrası uygulaması, gebe eğitimi ve danışmanlık, baba eğitimi, doğuma hazırlık eğitimi, gevşeme egzersizi 
ve rehberli imgeleme, bilişsel davranış̧̧ı terapiler, yoga ve meditasyon uygulamalarının prenatal bağlanmayı desteklediği gösterilmiştir. Kadın sağlığında çalışan hemşire ve ebeler, kadınlara gebe kaldıktan sonra bebekleri ile konuşmaları, onlara dokunmaları, hareketlerini hissettikten sonra saymalarını önerebilir. Ebe ve hemşirelerin düşük prenatal bağlanma riski olan gebelere ucuz, basit ve non-invaziv olan bu uygulamalar hakkında eğitim ve danı̧̧manlık vermesi, ayrıca gebenin kendisi için seçeceği uygun yöntemi kullanması konusunda desteklemesi önerilmektedir. Aynı zamanda ülkemizde prenatal bağlanmada kanıta dayalı uygulamaların etkinliğini test eden daha fazla randomize kontrollü çalışmaların yapılması önerilmektedir.

\section{Kaynaklar}

Abasi E, Tafazzoli M, Esmaily H, Hasanabadi H (2013) The effect of maternal-fetal attachment education on maternal mental health. Turk J Med Sci, 43:815-820.

Akbarzade $M$, Setodeh S, Sharif $F$, Zare N (2014) The effect of fathers' training regarding attachment skills on maternal-fetal attachments among primigravida women: a randomized controlled trial. Int J Community Based Nurs Midwifery, 2:259-267.

Akbarzadeh M, Moattari M, Abootalebi M (2017) Effect of the BASNEF model on maternal-fetal attachment in the pregnant women referring to the prenatal clinics affiliated to Shiraz University of Medical Sciences. Iranian Journal of Neonatology, 8(3):31-37.

Alan Dikmen H, Çankaya S (2018) Maternal obezitenin prenatal bağlanma üzerine etkisi. Acıbadem Üniversitesi Sağlık Bilimleri Dergisi, 9:118-123.

Alhusen JL, Hayat MJ, Borg L (2021) A pilot study of a group-based perinatal depression intervention on reducing depressive symptoms and improving maternal-fetal attachment and maternal sensitivity. Arch Womens Ment Health, 24:145-154.

Azogh M, Shakiba M (2018) The effect of cognitive behavioral training on maternal-fetal attachment in subsequent pregnancy following stillbirth. Hayat, 24:71-83.

Baghdari N, Sahebzad ES, Kheirkhah M, Azmoude E. (2016) The effects of pregnancy-adaptation training on maternal-fetal attachment and adaptation in pregnant women with a history of baby loss. Nurs Midwifery Stud, 5:e28949.

Baltacı N, Başer M (2020) Riskli gebelerde yaşanan anksiyete, prenatal bağlanma ve hemşirenin rolü. Dokuz Eylül Üniversitesi Hemşirelik Fakültesi Elektronik Dergisi, 13:206-212.

Bellieni CV, Ceccarelli D, Rossi F, Buonocore G, Maffei M, Perrone S et al. (2007) Is prenatal bonding enhanced by prenatal education courses? Minerva Ginocol, 59:125-129.

Celik M, Ergin A (2020) The effect on pregnant women's prenatal attachment of a nursing practice using the first and second Leopold's maneuvers. Jpn J Nurs Sci, 17:e12297.

Chang HC, Yu CH, Chen SY, Chen CH (2015) The effects of music listening on psychosocial stress and maternal-fetal attachment during pregnancy. Complement Ther Med, 23:509-515.

Chang S, Park S, Chung C (2004) Effect of Taegyo-focused prenatal education on maternal-fetal attachment and self-efficacy related to childbirth. Taehan Kanho Hakhoe Chi, 34:1409-1415.

Condon JT (1993) The assessment of antenatal emotional attachment: development of a questionnaire instrument. $\mathrm{Br} J$ Health Psychol, 66:167-183.

Cranley MS (1981) Development of a tool for the measurement of maternal attachment during pregnancy. Nurs Res, 30:281-284.

Çıtak Bilgin N, Ak B, Ayhan F, Öztürk Koçyiğit F, Yorgun S, Topçuoğlu MA (2020) Effects of childbirth education on prenatal adaptation, prenatal and maternal attachment. Anatolian Journal of Family Medicine, 3:128-135.

Çoban A, Saruhan A (2005) Anne-bebek etkileşiminde hemşirenin rolü. Ege Üniversitesi Hemşirelik Yüksek Okulu Dergisi, 21: 89-96.

Delaram M, Jafar-Zadeh L, Shams S (2018) The effects of fetal movements counting on maternal-fetal attachment: a randomised controlled trial. J Clin Diagn Res, 12(5):LC28-LC31.

Demirkan LT, Tastan K, Dane Ş (2020) Effectiveness of fetal movement counting and imagining fetus position to prenatal attachment and depressive symptoms in pregnant women in 24-28th gestational week. J Res Med Dent Sci, 8:184-188.

Duyan V, Kapısız SG, Yakut HI (2013) Doğum Öncesi Bağlanma Envanteri'nin bir grup gebe üzerinde Türkçeye uyarlama çalışması. Jinekoloji-Obstetrik ve Neonatoloji Tıp Dergisi, 10:1609-1614. 
Ekrami F, Mohammad-Alizadeh Charandabi S, Babapour Kheiroddin J, Mirghafourvand M (2019) The effect of counselling on depression and anxiety of women with unplanned pregnancy: a randomized controlled trial. Community Ment Health J, 55:10471056.

Elkin N (2015) Gebelerin prenatal bağlanma düzeyleri ve bunları etkileyen faktörler. Sürekli Tıp Eğitimi Dergisi, 24:230-236.

Erkal Aksoy Y, Dereli Yılmaz S, Aslantekin F (2016) Riskli gebeliklerde prenatal bağlanma ve sosyal destek. Turkiye Klinikleri Journal of Health Sciences, 1:163-169.

Gheibi Z, Abbaspour Z, Haghighyzadeh MH, Javadifar N (2020) Effects of a mindfulness-based childbirth and parenting program on maternal-fetal attachment: a randomized controlled trial among Iranian pregnant women. Complement Ther Clin Pract, 41:101226.

Golbasi Z, Ucar T, Tugut N (2015) Validity and reliability of the Turkish version of the Maternal Antenatal Attachment Scale. Jpn J Nurs Sci, 12:154-161.

Güney E, Ucar T (2019) Effect of fetal movement counting on the maternal antenatal attachment. Jpn J Nurs Sci, 16:71-79.

Gürol A, Ejder Apay S, Sönmez T (2020) Effects of the labour fear on the prenatal attachment and determination of the affecting factors. Arc Health Sci Res, 7:137-145.

Höbek Akarsu R, Rathfisch G (2018) The effect of pregnancy yoga on the pregnant's psychosocial health and prenatal attachment. Indian Journal of Traditional Knowledge, 17:732-740.

Höbek Akarsu R, Tuncay B, Yüzer Alsaç S (2017) Anne-bebek bağlanmasında kanıta dayalı uygulamalar. Gümüşhane Üniversitesi Sağlık Bilimleri Dergisi, 6:275-279.

Jangjoo S, Lotfi R, Assareh M, Kabir K (2019) Effect of counselling on maternal-fetal attachment in unwanted pregnancy: a randomised controlled trial. J Reprod Infant Psychol, doi: 10.1080/02646838.2019.1673891.

Karabulutlu Ö, Derya Beydağ K, Lazoğlu M (2020) Prenatal attachment levels and affecting factors of pregnant women living in İstanbul and Kars. Kafkas J Med Sci, 10:24-31.

Kartal YA, Karaman T (2018) Doğuma hazırlık eğitiminin gebelerde prenatal bağlanma ve depresyon riski üzerine etkisi. Zeynep Kamil Tıр Bülteni, 49:85-91.

Khalili Z, Navaee M, Shakiba M, Navidian A (2020) The effect of a supportive-educational intervention on maternal-fetal attachment of pregnant women facing domestic violence: randomized controlled trial. Iran J Psychiatry Behav Sci, 14:e92070.

Kim M, Gim W (2019) Development and effects of a loving-kindness and compassion meditation program to improve maternal-fetal attachment. Stress, 27:353-364.

Koç Özkan T, Şimşek Küçükkelepçe D, Aydın Özkan S (2020) Gebelikte prenatal bağlanma ve vücut algısı arasındaki ilişki ve etkileyen faktörler. Manisa Celal Bayar Üniversitesi Sağlık Bilimleri Enstitüsü Dergisi, 7:49-54.

Koptur A, Güner Emül T (2017). Fetüs ve yenidoğanda bağlanmanın iki yüzü: maternal ve paternal bağlanma. Ege Üniversitesi Hemşirelik Fakültesi Dergisi, 33:138-152

Kordi M, Fasanghari M, Asgharipour N, Esmaily H (2016) Effect of guided imagery on maternal-fetal attachment in nulliparous women with unplanned pregnancy. Journal of Midwifery and Reproductive Health, 4:723-731.

Küçükkaya B, Kahyaoğlu Süt H, Öz S, Altan Sarıkaya N. (2020) Gebelik döneminde çiftler arası uyum ve prenatal bağlanma arasındaki ilişki. Acıbadem Üniversitesi Sağlık Bilimleri Dergisi, 11:102-110.

Marzouk T, Nabil H (2015) Effect of a training program about materna-fetal attachment skills on prenatal attachment among primigravida women. IOSR Journal of Nursing and Health Sscience, 4:70-75.

Mehran P, Simbar M, Shams J, Ramezani-Tehrani F, Nasiri N (2013) History of perinatal loss and maternal-fetal attachment behaviors. Women Birth, 26:185-1789.

Mikhail MS, Freda MC, Merkatz RB, Polizzotto R, Mazloom E, Merkatz IR (1991) The effect of fetal movement counting on maternal attachment to fetus. Am J Obstet Gynecol, 165:988-991.

Mojahed S, Dafei M, Dehghani A, Shayegh Z (2019) Evaluation of the effect of midwifery counseling with cognitive-behavioral approach on maternal-fetal attachment in the pregnant women with abortion history. J Adv Pharm Edu Res, 9(S2):119-125.

Mokaberian M, Dehghanpouri H, Faez N, Vosadi E (2021) The effect of progressive muscle relaxation with imagery-based relaxation on the mental health and maternal-fetal attachment in women with a first unwanted pregnancy. Int J Health Stud, 7:11-16.

Muller ME (1993) Development of the Prenatal Attachment Inventory. Western J Nurs Res, 15:199-211.

Mutlu C, Yorbik Ö, Tanju IA, Çelikel F, Sezer RG (2015) Doğum öncesi, doğum sırası ve doğum sonrası etkenlerin annenin bağlanması ile ilişkisi. Anadolu Psikiyatri Derg, 16:442-450. 
Nacar G, Timur Taşhan S (2019) Gebelerin uyku özelliklerinin prenatal bağlanma ile ilişkisi. Erciyes Üniversitesi Sağlık Bilimleri Dergisi, 28:164-171.

Nishikawa M, Sakakibara H (2013) Effect of nursing intervention program using abdominal palpation of Leopold's maneuvers on maternal-fetal attachment. Reprod Health,10:12.

Özdemir K, Çevirme A, Başkaya Y (2020) Anxiety and prenatal attachment levels in pregnancy and influencing factors. Cukurova Med J, 45:502-510.

Peppers LG, Knapp RJ (1980) Maternal reactions to involuntary fetal/infant death. Psychiatry, 43:155-159.

Rincy K, Nalini S (2014) Effect of fetal movement counting on prenatal attachment and maternal worries among primigravidae. Asian J Nurs Education Res, 4:224.

Rubin R (1975) Maternal tasks in pregnancy. Matern Child Nurs J, 4:143-153.

Saastad E, Israel P, Ahlborg T, Gunnes N, Frøen JF (2011) Fetal movement counting-effects on maternal-fetal attachment: a multicenter randomized controlled trial. Birth, 38:282-293.

Salehi K, Salehi Z, Shaali M (2017) The effect of education of fetal movement counting on maternal-fetal attachment in the pregnant women: A randomized controlled clinical trial. Int J Pediatr, 5:4699-4706.

Shin HS, Kim JH (2011) Music therapy on anxiety, stress and maternal — fetal attachment in pregnant women during transvaginal ultrasound. Asian Nurs Res, 5:19-27.

Toosi M, Akbarzadeh M, Ghaemi Z (2017) The effect of relaxation on mother's anxiety and maternal-fetal attachment in primiparous IVF mothers. J Nat Med Ass, 109:164-171.

Toosi M, Akbarzadeh M, Sharif F, Zare N (2014) The reduction of anxiety and improved maternal attachment to fetuses and neonates by relaxation training in primigravida women. Womens Health Bull, 1:e18968.

Topaç Tunçel N, Kahyaoğlu Süt H (2019) Gebelikte yaşanan anksiyete, depresyon ve prenatal distres düzeyinin doğum öncesi bebeğe bağlanmaya etkisi. Jinekoloji-Obstetrik ve Neonatoloji Tıp Dergisi, 16:9-17.

Türkmen Çevik F, Kurnaz FB (2019) Prenatal Bağlanma Ölçeği: güvenirlik ve geçerlik çalışması. H.Ü. Sağlık Bilimleri Fakültesi Dergisi, 6:112-138.

Ustunsoz A, Guvenc G, Akyuz A, Oflaz F (2010) Comparison of maternal-and paternal-fetal attachment in Turkish couples. Midwifery, 26(2):e1-9.

Yılmaz SD, Beji NK (2010) Gebelerin stresle başa çıkma, depresyon ve prenatal bağlanma düzeyleri ve bunları etkileyen faktörler. Genel Tıp Dergisi, 20:99-108.

Yılmaz SD, Beji NK (2013) Prenatal Bağlanma Envanterinin Türkçéye Uyarlanması: güvenilirlik ve geçerlilik çalışması. Anadolu Hemşirelik ve Sağlık Bilimleri Dergisi, 16:103-109.

Yılmaz SD (2013) Prenatal anne-bebek bağlanması. Hemşirelikte Eğitim ve Araştırma Dergisi, 10:28-33.

Yazarların Katkıları: Yazarlar çalışmaya önemli bir bilimsel katkı sağladıklarını ve makalenin hazırlanmasında veya gözden geçirilmesinde yardımcı olduklarını kabul etmiştir.

Danışman Değerlendirmesi: Dış bağımsız.

Çıkar Çatışması: Yazarlar çıkar çatışması bildirmemiştir.

Finansal Destek: Yazarlar bu çalışma için finansal destek almadığını beyan etmiştir.

Authors Contributions: The authors attest that they have made an important scientific contribution to the study and have assisted with the drafting or revising of the manuscript.

Peer-review: Externally peer-reviewed.

Conflict of Interest: No conflict of interest was declared by the authors.

Financial Disclosure: The authors declared that this study has received no financial support. 